\title{
Accidents and Risk Related Behaviours in Downhill Mountain Biking in Regard to Trail Choice
}

\author{
A. Frühauf, M. Huter, E. Weiß, M. Kopp \\ Department of Sport Science, University of Innsbruck, Innsbruck, Austria
}

\author{
CORRESPONDING AUTHOR: \\ Anika Frühauf \\ Department of Sport Science \\ University of Innsbruck \\ Fürstenweg 185 \\ 6020 Innsbruck, Austria \\ E-mail: anika.fruehauf@uibk.ac.at
}

DOI:

10.32098/mltj.02.2020.12

LEVEL OF EVIDENCE: $3 b$

\begin{abstract}
SUMMARY
Background. Downhill mountain biking (DMB) is a subdiscipline of mountain biking. Rider skill seems to be the most influencing variable for DMB performance. In order to classify skill level, the aim of the present study was to investigate DMB-participants in terms of accident involvement, demographic and psychological variables, and to categorize them after their completion of trails (easy vs difficult) in a bike park.

Methods. 190 DMB riders (DMBR) were asked about their accidents, injuries and psychological variables at two different bike parks (table I). 112 answered the questionnaire after completing an easy trail (ET; $4^{3}+\mathrm{B}$ or $\left.4^{2}+\mathrm{B}\right)$ and 78 after a difficult trail (DT; $8^{3}+\mathrm{B}$ or $\left.8+\mathrm{B}\right)$. To calculate group differences, Mann-Whitney $\mathrm{U}$ and $\mathrm{Chi}^{2}$ Tests were used.

Results. Significant differences detected that DT riders were younger, consisted of more males, had more experience in years and higher frequency per week than ET riders. No significant difference was found in accident involvement. All but one person reported to wear at least a helmet as protection equipment. Knee and back protection usage was significantly higher in DT riders. DT riders perceived their sport as more dangerous, reported higher deliberate risk-taking and experienced higher sensations during DMB. Conclusions. The differences between ET riders and DT riders show the need of preventive steps, such as risk assessment capability, even for more experienced riders.
\end{abstract}

KEY WORDS

High-risk sports; extreme sports; motives; protection equipment.

\section{BACKGROUND}

Mountain biking was started in the USA in 1976 (1). As with many adventure sports, mountain biking originated as a niche activity. Today, however, it involves many, clearly distinguished subdisciplines such as Cross-Country, Dirt Jumping, Freeride, All-Mountain/Enduro and Downhill Mountain Biking (DMB) (1). DMB is a racing-oriented subdiscipline of Mountain Biking consisting of high velocity runs (up to $70 \mathrm{~km} / \mathrm{h}$ ), jumps and narrow turns on hard, rocky and uneven terrain which involves the risk of serious, even fatal injuries $(2,3,1)$. Cohen et al (2018) (4) suggested using the term extreme/high-risk sports when referencing a sport which is "a predominantly competitive (comparison or self-evaluative) activity within which the participant is subjected to natural or unusual physical and mental challenges such as speed, height, depth, or natural forces. More- over, an unsuccessful outcome is more likely to result in the injury or fatality of the participant more often than in a 'non-extreme sport'" (p. 6).

Accidents and injuries occur frequently in DMB. In a prospective study of one summer season (April-September), 494 injuries occurred in 249 questioned riders. Most of these injuries were mild $(65 \%)$ with contusions and abrasions as the major injury types $(56 \%$ and $64 \%)$. Of the injuries, $13 \%$ were severe; $41 \%$ of which led to restraint from $\mathrm{DMB}$ of more than 28 days (2). In a retrospective data collection of competitive and recreational DMB athletes, competitive athletes had a significantly higher injury rate than recreational ones $(79 \%$ vs $50 \%)$, but also had a higher exposure time $(16.3 \pm 9.5 \mathrm{~h} /$ week vs $7.4 \pm 5.8 \mathrm{~h} /$ week) (5). When normalizing for time of participation, the incidence of injuries was only slightly higher in World Cup athletes 
than in recreational athletes $(0.69$ vs 0.60 injuries $/ 1000 \mathrm{~h}$ of exposure). Despite the inherent risks, extreme sports have gained popularity in recent decades, involving both elite and recreational athletes (6).

From a psychological point of view, recent research suggests that extreme sport participants are not one homogenous group of risk-takers driven by their desire for thrill (7-9). Rather, motives for extreme sport participation differ between the activities (10). Some extreme sport participants, such as skydivers, seem motivated by the sensations of the activities, whereas mountaineers may be motivated by the agentic and emotion-regulating effects of their activity (10). The difference might occur due to the differing demands of each activity. Skydiving is brief and intense but easily accessible, whereas mountaineering requires extended periods of physical exertion and has high barriers to entry.

A DMB race is reported to be between 2-5 minutes (11). Since the activity it is short in duration and easily accessible (especially for those who travel up the mountain via cable car), it could, therefore, be categorized as a thrill-seeking activity. Important variables that influence downhill performance are, in decreasing order of importance; rider skill, handgrip endurance, self-confidence and aerobic capacity (11). Many extreme sport activities can be carried out at varying levels of difficulty (12). In DMB, trails vary in steepness, narrowness, turn radius and trail condition, requiring higher skills of the riders on more difficult trails. Since rider skill is the most influential variable on downhill performance, the aim of this study was to propose a new approach for studying participation variables and outcomes in a specific discipline, depending on the rider skill level of participants.

\section{METHODS}

\section{Trail categorization}

Trails were categorized using the Mountain bike Trail Difficulty Scale (MTDS; 13) (table I) which ranks trail difficulty and danger based on numbers, exponents and letters according to the following equation:

$$
\text { number }{ }^{\text {exponent }}+\text { Letter }
$$

The number describes the difficulty of the trail based on width gradient and quality (see Table 1 for a comparison of the two evaluated trails 4 and 8 ). The exponent describes the jump difficulty $\left({ }^{2}=\right.$ Jumps with good landings/no dangerous gaps/ small to middle heights; ${ }^{3}=$ Jumps with good landings of greater heights/ necessity to jump over gaps but no greater danger; ${ }^{4}=$ jumps with dangerous gaps and difficult landings but without great height). Letters ranging from $B$ to $E$
Table I. Characteristics of trail category 4 and 8 by the mountain bike trail difficulty scale.

\begin{tabular}{|c|c|c|}
\hline & 4 & 8 \\
\hline Trail width: & narrow 0,5 to $1,5 \mathrm{~m}$ & $\begin{array}{l}\text { narrow } 0,5 \text { to } 1,5 \mathrm{~m} \text { to } \\
\text { extreme narrow }(<0,5 \mathrm{~m})\end{array}$ \\
\hline Gradient: & $\begin{array}{l}\text { middle to steep } \\
10-20 \%\end{array}$ & $\begin{array}{l}\text { very steep }(20-40 \%) \text { to } \\
\text { extreme steep }(>40 \%)\end{array}$ \\
\hline Condition: & $\begin{array}{l}\text { low branches, } \\
\text { Stones, good grip }\end{array}$ & $\begin{array}{l}\text { low to high branches, big } \\
\text { Stones, extremely blocked } \\
\text { trail }\end{array}$ \\
\hline Turn radius: & narrow curves & $\begin{array}{l}\text { Hairpin turns and narrow } \\
\text { hairpin turns (necessity of } \\
\text { moving the back wheel) }\end{array}$ \\
\hline
\end{tabular}

are used to describe the likelihood and danger of potential falls while riding the trails. A ranking of $B$ describes trails where falls are possible from a low height into relatively safe terrain, whereas on $\mathrm{E}$ trails, crashes due to riding errors are likely and potentially life threatening.

\section{Procedure}

256 downhill mountain bike riders (DMBR) were questioned at two different bike parks after finishing either an easy categorized trail $\left(4^{3}+\mathrm{B}\right.$ or $\left.4^{2}+\mathrm{B}\right)$ or a difficult categorized trail $\left(8^{3}+\mathrm{B}, 8+\mathrm{B}\right.$, or $\left.8^{4}+\mathrm{B}\right)$. Trails were noted and integrated in the questionnaire. In the difficult trail category, a high level of skill is necessary, whereas, the easy trail could be completed without specific downhill skills. 66 DMBR only answered the first page of the questionnaire and therefore, were excluded, resulting in 190 datasets to analyze. 112 answered the questionnaire after riding an easy trail (ET) and 78 after a difficult trail (DT).

\section{Questionnaire}

The questionnaire consisted of demographic variables (age, gender), specific variables related to DMB participation (experience, frequency, accident occurrence), injury type and psychological scales. Injury type was more well-defined, to include affected body part(s). The psychological scales included the Sensation Seeking, Emotion Regulation and Agency Scale (SEAS (10)), the Risk-Taking Inventory (RTI(14)) and the Risk-Taking Behaviour Scale (RBS$\mathrm{K}(15))$.

The SEAS 'While-inventory' evaluates the experience of sensation seeking, emotion regulation and agency while participating (10). The German Version (G-SEAS (16)) consists of 14-items and is rated on a 7-point Likert scale. Good internal consistency and a correlation with estab- 
lished measures of sensation seeking, emotion regulation and agency was shown $(10,16)$.

The RTI measures risk-taking in high-risk sports across two opposing factors: deliberate risk-taking (DRT, three items) and precautionary behaviors ( $\mathrm{PB}$, four items). They are measured on a seven item, five-point Likert-scale-ranging from one (never) to five (always) (14). The German version (G-RTI; (16)) showed a good model fit and internal consistency.

As a further indicator of risk-taking behavior, the German version of the RBS-K (17) was used. It is a three items scale scored on a 5-point Likert scale-ranging from one (strongly disagree) to five (strongly agree). This scale allows classification of the participants into risk-prone (total mean + standard deviation) and risk-averse people (total mean standard deviation). All participants in between this range are defined as neutral. Internal consistency was shown across different language versions $(15,18,17)$.

\section{Statistical analyses}

Data are presented as means and standard deviations, and as absolute and relative frequencies. Chi-square tests and Mann-Whitney U tests were used to calculate differences between the groups of DT riders and ET riders. The analysis was done using IBM SPSS Statistics 23.0. All p-values were two-tailed and values of $\mathrm{p}<0.05$ were considered to indicate statistical significance.

\section{RESULTS}

In total, the population consisted of $26.7 \%$ females and $72.3 \%$ males, with a mean age of $31.12 \pm 8.56$ years and a mean experience of $8.04 \pm 7.41$ years in DMB. The majority $(58 \%)$ of the sample population participate two to three days per week in their activity, $25.2 \%$ participate once per week and $16.3 \%$ participate more than 4 days per week. Comparing both cohorts, there was a significant difference in age and gender alike. Younger people and fewer women rode the more difficult trails (table II). Additionally, DT riders had more experience and higher riding frequency. Almost half of DMBR experienced an accident $(n=98)$, with no significant difference seen between the groups: $43.9 \%$ of ET riders and $57.8 \%$ of DT riders. The majority of accidents were reported to be due to the rider's own fault. Only two subjects reported an accident due to another rider's fault. Very few riders who experienced an accident $(16 \%$ ET and 52\% DT) could recall their injury type and location. The majority of reported injuries were contusions and abrasions (ET: 5, 71\%; DT, 21, 84\%). DT riders differed in bone fractures (ET 1, 14\%; DT: 9, 36\%). Three of DT riders reported craniocerebral trauma and one of DT riders reported a spinal cord injury. Injury locations were similarly distributed on upper and lower extremity, and injuries to the internal organs were reported by one person of each cohort.

In terms of protection equipment, all but one person (ET) reported riding with a helmet. Every DT participant noted

Table II. Demographics.

\begin{tabular}{|c|c|c|c|}
\hline & Easy Trail $(n=114)$ & Difficult Trail ( $n=83$ ) & Significance \\
\hline Age & $32.24(9.26)$ & $29.48(8.71)$ & $.039 \% \mathrm{~b}$ \\
\hline Gender & $\begin{array}{l}\text { female: } 38(33.6 \%) \text { male: } 75 \\
(66.4 \%)\end{array}$ & $\begin{array}{l}\text { female: } 15(18.1 \%) \text { male: } 68 \\
(81.9 \%)\end{array}$ & $.015 * a$ \\
\hline Experience [years] & $7.48(7.62)$ & $8.71(7.10)$ & $.029 * \mathrm{~b}$ \\
\hline Frequency [1/week] & $37(32.5 \%)$ & $13(15.7 \%)$ & \multirow{3}{*}{$.025 * a$} \\
\hline [2-3/week] & $61(53.5 \%)$ & $53(63.9 \%)$ & \\
\hline [>4/week] & $16(14 \%)$ & $17(20.5 \%)$ & \\
\hline No Accident & $64(56.1 \%)$ & $35(42.2 \%)$ & \multirow{4}{*}{$.162^{\mathrm{a}}$} \\
\hline 1 accident & $20(17.5 \%)$ & $14(16.9 \%)$ & \\
\hline 2 accidents & $13(11.4 \%)$ & $16(19.3 \%)$ & \\
\hline$>2$ accidents & $17(14.9 \%)$ & $18(21.7 \%)$ & \\
\hline Third party responsibility & $2(4.0 \%)$ & $0(0.0 \%)$ & \multirow{3}{*}{$.342^{a}$} \\
\hline Own responsibility & $43(86.0 \%)$ & $45(91.8 \%)$ & \\
\hline Both & $5(10.0 \%)$ & $4(8.2 \%)$ & \\
\hline
\end{tabular}

Note: * $\mathrm{p}<.05,{ }^{\mathrm{a}} \mathrm{Chi}$-square analyses, ${ }^{\mathrm{b}} \mathrm{Mann}$-Whitney-U Test, numbers are presented as means \pm standard deviation or absolute and relative frequencies. 
wearing a helmet and most frequently, gloves, knee protection and back protection (table III). A neck brace was reported by $4 \%$ of both cohorts. The choice of shoes did not make a difference between the cohorts. A significantly higher use of back protection and knee protection was seen in DT riders compared to ET riders.

DT riders had higher deliberate risk-taking and higher sensation-seeking scores than ET riders (table IV). DT riders perceived their sport as more dangerous than ET riders. There was also a significant difference in the experience of sensations between both cohorts. Precautionary Behavior, Agency and Emotion Regulation did not differ between the groups. The group of risk-averse rider was smaller in DT than ET, however, there was no statistical significance.

\section{DISCUSSION}

The aim of the study was to assess DMBR of easy and difficult trails. ET and DT riders differed significantly in demographic variables, safety equipment and psychological outcomes. Accident occurrence did not differ between ET riders and DT riders. Although a minority of those who experienced an accident made a detailed statement to injury type and affected body part, it seems that DT riders endured more serious injuries (bone fracture, craniocerebral trauma). More serious injuries, such as fractures, were also reported by DMB World Cup athletes compared to recreational athletes (5). Since the difficult trails are more challenging (see comparison in methods), it is possible that faults within this difficulty have more serious consequences for DMBR. Comparing DT riders and ET riders in the present study with recre-

Table III. Protection equipment used at the time of the survey.

\begin{tabular}{llll}
\hline Type of Protection & Easy Trail & Difficult Trail & Significance \\
\hline MTB helmet & $58(51 \%)$ & $33(40 \%)$ & .122 \\
\hline Full-face helmet & $54(47 \%)$ & $51(60 \%)$ & .051 \\
\hline Goggle & $80(70 \%)$ & $63(76 \%)$ & .373 \\
\hline Gloves & $99(87 \%)$ & $75(90 \%)$ & .448 \\
\hline Protection jacket & $24(21 \%)$ & $11(13 \%)$ & .157 \\
\hline Knee protection & $87(76 \%)$ & $80(96 \%)$ & $<.001^{* *}$ \\
\hline Elbow protection & $42(37 \%)$ & $36(43 \%)$ & .355 \\
\hline Back protection (incl. Backpack) & $62(54 \%)$ & $68(82 \%)$ & $<.001^{* * *}$ \\
\hline Klickshoes & $28(25 \%)$ & $21(25 \%)$ & .124 \\
\hline Mountainbike shoes & $63(55 \%)$ & $54(65 \%)$ & \\
\hline Regular shoes & $23(20 \%)$ & $8(10 \%)$ & \\
\hline
\end{tabular}

Note: numbers are presented as absolute and relative frequencies ${ }^{*} \mathrm{p}<.05,{ }^{* *} \mathrm{p}<.01$.

Table IV. Psychological outcomes.

\begin{tabular}{lllc}
\hline Psychological Outcomes & Easy Trail & Difficult Trail & Significance \\
\hline DRT & $2.69(.12)$ & $3.40(.15)$ & $.001^{\mathrm{b} * *}$ \\
\hline PB & $4.83(.12)$ & $4.95(.15)$ & $.358^{\mathrm{b}}$ \\
\hline SEAS_SS & $4.55(.12)$ & $5.01(.12)$ & $.009^{\mathrm{b} * *}$ \\
\hline SEAS_ER & $4.35(.13)$ & $4.62(.15)$ & $.134^{\mathrm{b}}$ \\
\hline SEAS_AG & $5.64(.08)$ & $5.72(.09)$ & $.313^{\mathrm{b}}$ \\
\hline RBS risk-loving & $18(15.8 \%)$ & $16(19.3 \%)$ & $.533^{\mathrm{a}}$ \\
\hline RBS risk-averse & $23(20.2 \%)$ & $12(14.5 \%)$ & \\
\hline RBS neutral & $73(64.0 \%)$ & $55(66.3 \%)$ & $.043^{*} \mathrm{~b}$
\end{tabular}

Note: psychological outcomes $* * \mathrm{p}<.01, * \mathrm{p}<.05$, DRT deliberate risk-taking, PB precautionary behaviour, SEAS_SS Sensation Seeking, SEAS_ER Emotion

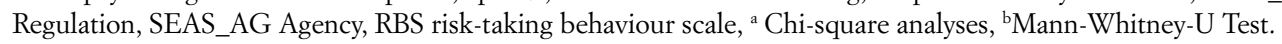


ational DMB and DMB World Cup Athletes of Himmelreich (5), showed the more skilled rider cohort (DT riders and DMB World Cup Athletes) were younger and had a higher riding frequency than both of the other cohorts. However, the cohorts of DT riders and DMB World Cup Athletes by Himmelreich (5) differ in their age (DT: 29.5 years vs 23.1 years). When setting the injury occurrence in proportion to exposure time, the difference in injuries between the cohorts of recreational and professional DMBR was only minor (5). In the present study, DT riders had significantly higher experience in their sport and higher riding frequency per week, thus higher exposure time in DMB. Compared to the cohort of Becker et al. (2013) (2), the participants of the present study had higher experience in $\mathrm{DMB}$ ( $>7$ years vs 4 years). In terms of protection equipment, all but one person wore at least a helmet. Becker et al. (2013) (2) reported that $96 \%$ of all riders wore full face helmets, and in the present study, those were only $47 \%$ of ET riders and $61 \%$ of DT riders. A neck brace was only worn by 8 people in the present study compared to $34 \%$ in the population by Becker et al. (2). There was also a significant difference between ET and DT riders using back protection and knee protection, with higher usage in DT riders.

DT riders perceived their sport as more dangerous compared to ET riders. DT riders had a significantly higher use of protection equipment than ET riders, but also had a higher score in deliberate risk-taking. Freeriders reported to have changed their behaviour after experiencing an accident or close call towards higher precautionary behavior (9), but a difference in the assessment of precautionary behavior was not seen between ET riders and DT riders. However, the usage of higher knee and back protection could be interpreted as a higher precautionary behavior in terms of protection equipment. With data showing that DT riders experience more serious injuries, the experience of injuries might lead to a different realization of the risks involved and thus, a different perception of the dangerousness of the sport.

The experience of thrill during the activity differed significantly between the cohorts in the present study. In previous studies, sensation-seeking means were higher in freeriders (7) and both mountaineers and skydivers (10) than they were in DMBR of the present study. However, the experience of Agency showed comparable means to the cohorts of freeriders and both mountaineers and skydivers $(7,10)$. Since no control group was assessed, it cannot be concluded if DMB is a thrill-seeking activity. However, DT riders experienced higher sensations throughout the activity and reported to take more deliberate risks. Sensation-seeking and deliberate risk-taking have shown to be positively related in previous studies $(16,14)$.
A difference in the categorization of DT riders and ET riders as risk-loving and risk-averse persons was not seen. The vast majority of all accidents were reported to be due to the rider's own fault without any third-party responsibilities. This is comparable to Becker et al. (2) who reported rider's fault as the most common fault for accident occurrence. Although DT riders perceive their sport as dangerous and more dangerous than ET riders, prevention strategies in terms of risk-assessment capabilities could be implemented. Protection equipment use was high in the present study and was reported to be especially high in young mountain bikers (19). Craniocerebral Trauma was surprisingly low in the present study compared to other studies $(2,5)$, which might have been prevented with the use of protection equipment.

\section{Strength and limitations}

This study used a unique cohort since, within an extreme sport activity (a mountain bike sub-discipline) to differentiate difficulty levels after a trail was completed. Being that it is difficult to classify many extreme sports, the results of this study's methods may serve in the future to differentiate other adventure or extreme sports based on their conceptualization. (12). Although experience was assessed, no conclusions could be drawn towards injuries per hour. With a mean experience of 7 years, ET riders still showed higher experience compared to prior studies in DMB. Only $16 \%$ of ET riders and $52 \%$ of DT riders who experienced an accident with medical treatment could recall injury type and location. Accident occurrence was not limited to a time frame, and no information of time of accident or injury occurrence was asked. Although participants were questioned in the bike park after completion of their trails, data of injuries and accidents were collected retrospectively on previous accidents/injuries within the last years. Questionnaires were self-evaluated and no medical assistance for classifying injuries was provided. The retrospective nature of many studies on extreme sports is a common problem (20), and they are also limited by recall bias (2). Since no control group was assessed no conclusions can be drawn towards low-risk sports.

\section{CONCLUSIONS}

This study focused on a specific sub-discipline of mountain biking and used a unique cohort of DMB riders from easy and difficult trails. Accident occurrence did not differ significantly between the cohorts. However, DMB riders of difficult trails scored higher on deliberate risk-taking measurements and perceived their sport as more dangerous than DMB riders of easy trails. The vast majority of acci- 
dents are reported as one's own fault with an even higher self-responsibility and injury rate in DMB riders of difficult trails. Since those riders also wore significantly more protection equipment, preventive steps for higher skilled riders should include steps towards a better risk-assessment capability. The right use of protection equipment should

\section{REFERENCES}

1. Becker J, Moroder P. Extreme Mountain Biking Injuries. In: Feletti F, editor. Extreme Sports Medicine. Cham: Springer International Publishing; 2017; 139-50.

2. Becker J, Runer A, Neunhäuserer D, Frick N, Resch H, Moroder P. A prospective study of downhill mountain biking injuries. British Journal of Sports Medicine 2013; 47(7):458-62.

3. Kronisch RL, Pfeiffer RP. Mountain Biking Injuries. Sports Medicine 2002; 32(8):523-37. Available from: URL: https:// doi.org/10.2165/00007256-200232080-00004.

4. Cohen R, Baluch B, Duffy LJ. Defining Extreme Sport: Conceptions and Misconceptions. Front. Psychol. 2018; 9:1974.

5. Himmelreich H, Pralle H, Vogt L, Banzer W. Mountainbikeverletzungen bei Leistungs- und Breitensportlern. Sportverletz Sportschaden 2007; 21(4):180-4.

6. Pain MTG, Pain MA. Essay: Risk taking in sport. The Lancet 2005; 366: S33-S34.

7. Frühauf A, Anewanter P, Hagenauer J, Marterer N, Kopp M. Freeriding-Only a need for thrill? : Comparing different motives and behavioural aspects between slope skiers and freeride skiers. Journal of Science and Medicine in Sport 2018.

8. Barlow M, Woodman T, Chapman C, Milton M, Stone D, Dodds $\mathrm{T}$ et al. Who takes risks in high-risk sport? : The role of alexithymia. J Sport Exerc Psychol 2015; 37(1):83-96.

9. Frühauf A, Hardy WAS, Pfoestl D, Hoellen F-G, Kopp M. A Qualitative Approach on Motives and Aspects of Risks in Freeriding. Front. Psychol. 2017; 8:141.

10. Barlow M, Woodman T, Hardy L. Great expectations: different high-risk activities satisfy different motives. J Pers Soc Psychol 2013; 105(3):458-75.

11. Chidley JB, MacGregor AL, Martin C, Arthur CA, Macdonald $\mathrm{JH}$. Characteristics explaining performance in downhill mountain biking. Int J Sports Physiol Perform 2015; 10(2):183-90. be explained to all DMB riders, but especially targeted for DMB riders of easier trails.

\section{CONFLICT OF INTERESTS}

The authors declare that they have no conflict of interests (21).

12. Buckley RC. To Analyze Thrill, Define Extreme Sports. Front. Psychol. 2018; 9:1216.

13. BIKEACADEMY. Mountainbike Trail Difficulty Scale (MTDS); 2018 [cited 2019 Mar 29]. Available from: URL: http://bikeacademy.at/mtds-singletrail-skala.html.

14. Woodman T, Barlow M, Bandura C, Hill M, Kupciw D, Macgregor A. Not all risks are equal: the risk taking inventory for high-risk sports. J Sport Exerc Psychol 2013; 35(5):479-92.

15. Castanier C, Le Scanff C, Woodman T. Who takes risks in high-risk sports? A typological personality approach. Res Q Exerc Sport 2010; 81(4):478-84.

16. Frühauf A, Hardy WAS, Roberts R, Niedermeier M, Kopp M. Structural validation of three German versions of behavioral and motivational scales in high-risk sports. Ger J Exerc Sport Res 2018; 103(3):411.

17. Frühauf A, Niedermeier M, Ruedl G, Barlow M, Woodman T, Kopp M. Deutschsprachige Übersetzung und Validierung der Risikobereitschaftskurzskala (RBS-K) für Risikosportarten. Sportverletz Sportschaden 2017.

18. Lafollie D, Le Scanff C. Détection des personnalités à risque dans les sports à sensations fortes. L'Encéphale 2007; 33(2):135-41.

19. Emery CA. Injury prevention in kids' adventure and extreme sports: future directions. Res Sports Med 2018; 26(sup1):199-211.

20. Feletti F, Brymer E. Injury in kite buggying: the role of the 'out-of-buggy experience'. J Orthop Surg Res 2018; 13(1):104.

21. 21. Padulo J, Oliva F, Frizziero A, Maffulli N. Muscles, Ligaments and Tendons Journal - Basic principles and recommendations in clinical and field Science Research: 2018 update. MLTJ 2018; 8(3): 305 - 307. 